\title{
Richard L. Day_The Quintessential Skeptical Inquirer Presentation of the Howland Award 1986'
}

\author{
WILLIAM A. SILVERMAN
}

The thought of our past years in me doth breed

Perpetual benediction ...

Not for these I raise

The song of thanks and praise;

But for those obstinate questionings

Of sense and outward things,

Fallings from us, vanishings ...

William Wordsworth

What would John Howland say if he were here today, and, I wonder, what would be the reaction of Ned Park, the first Howland awardee? I suspect the very size of the APS would render both men speechless. When Howland presented his first paper to this Society in 1906 at the Hotel Traymore, Atlantic City, there were 54 members (1). Forty-six years later, when the initial award was presented to Park in 1952 at the Hotel Chamberlin, Old Point Comfort, membership had increased about $31 / 2$ fold to 197. Today, when we meet to present the Howland Award for the 35 th time, the Society is 20 times larger than in Howland's day (membership in 1986 is 1116) (Brown AK, personal communication).

Despite gross changes in the Society-size is the easily measured but least important of many alterations that have taken place-is there a thread that connects current pediatric researchers to the time of Howland and later Park? The link is to be found, I suggest, by examining a singular frame of mind found in persons honored in the annual ceremony. Recall that John Howland (1873-1926) was a skeptic-he did not believe respected authorities who taught that "dyspnea, restlessness, stupor and coma in infants suffering from severe diarrhea are the result of toxic effects of the products of intermediary metabolism." (2). $\mathrm{He}$ (and Marriott) demonstrated, and reported to this Society in 1915 (1), that severe diarrhea was accompanied by loss of base producing an acidotic state and that the derangement could be corrected by intravenous sodium bicarbonate (3). The first 34 recipients of the Society's award have kept alive Howland's critical attitude toward received wisdom-they have all been doubters. It is my very great pleasure today to present the 35 th in this line of skeptics who have spent their lives trying to make sense out of information. Moreover, I will present evidence that the doubting of today's honoree goes beyond even that of John Howland who suspended disbelief for a brief spell when he argued that an enlarged thymus (more than $15 \mathrm{~g}$ ) was the cause of sudden infant death syndrome (4). Richard L. Day has been an unregenerate disbeliever-he is the quintessential skeptical inquirer.

Dick Day was born in New York City in 1905 and grew up in the town of Summit, NJ. After schooling in Summit and Short Hills, he spent 2 years at Choate, followed by Harvard undergraduate, Harvard Medical School, and on to Babies Hospital

Reprint requests Dr. William A. Silverman, 90 LaCuesta Drive, Greenbrae, CA 94904.

' Presented at the American Pediatric Society meeting, Washington, D.C., May $6,1986$. where he trained as a pediatric house officer in 1933. He practiced pediatrics in Ridgewood, $\mathrm{NJ}$ for about 6 months when he received an invitation to join the full-time staff in the Department of Pediatrics, College of Physicians and Surgeons, Columbia University.

In 1937, he went to Cornell's New York Hospital to work with Samuel Z. Levine and Harry H. Gordon in their ongoing studies of the metabolism of premature infants. James Hardy, physicist turned physiologist who later became the dean of American temperature physiologists, recalls his first meeting with Dick at Cornell: "It was a Fall day in the late 1930's that a tall, blond and very earnest young doctor came through the door which separated my office from the pediatric wing of New York Hospital. He said he wanted to make direct measurements of heat loss in premature babies in the manner of Lusk and DuBois. I was a young physicist, who had recently entered the world of medical research, and I was much impressed by Dr. Day's great desire to make precise measurements of babies' heat exchange even at the expense of much effort. He was not at all discouraged after I arranged to have him observe an experiment with the large adult-size calorimeter at the Russell Sage Institute. This instrument required three experienced observers at all times during a 'run,' and the assistance of a nurse and several laboratory technicians to gather the necessary data. None of this display of complexity and difficulty had the slightest effect on Dick Day; he was just as enthusiastic as ever.

We began to work on an idea that occurred to me while working with the large device; why not measure the rate of heat flow from the enclosure by means of thermal gradients between the inside and the outside of a baby calorimeter? The idea was to let the heat escape and measure it by means of difference in temperature between the interior and exterior of the box. Dick was delighted with the idea and looking me in the eye said, 'Wonderful, what shall I do next?'

For two years we worked away with an 'artificial baby' in the form of a copper cylinder the size of a 'preemie' (Fig. 1), alcohol checks and electric checks, finally achieving a precision about equivalent to that of the Sage calorimeter (Fig. 2) -nothing less was acceptable.

All during this time we talked science, politics and physiology. Dick was an exciting person with all sorts of unusual ideas. By that time I was being swept up in the preparations for war and our paths separated; we did not meet again for thirty years. However, we published our paper describing the first 'gradient calorimeter,' an instrument which is now used, with modifications, worldwide."

The classic studies, to which Hardy refers, were reported in March 1943 (6). In the paper, Dick Day described measurements obtained in 24 asymptomatic premature infants and, for the first time, the quantitative details of thermoregulation in newborn infants were documented. No unique physiology was uncovered; the responses of the infants were consistent with homoiothermy. The mechanisms were merely inefficient, in the face of prodigious heat loss and inadequate sweating, when compared with 


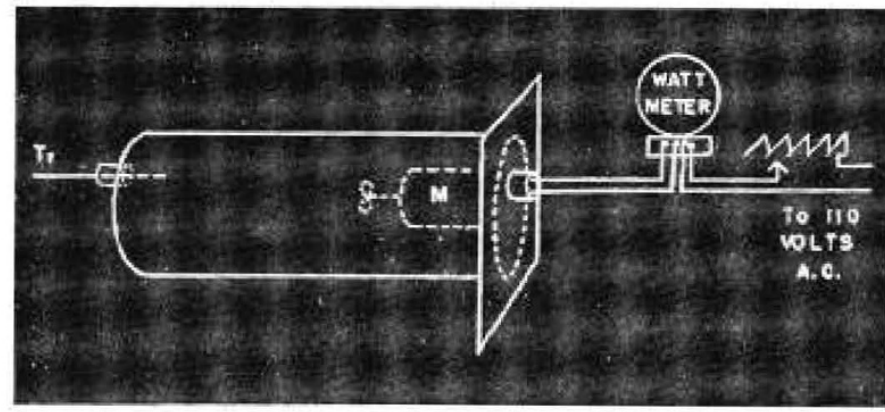

Fig. 1. The Day-Hardy artificial baby was a water-filled copper cylinder (5). It was painted black to imitate the perfect black-body-radiator property of human skin. One end was capped by a flange which held the underwater motor. It served as the source of heat, measured by a watthour meter, and it also stirred the water. A thermocouple measured changes in temperature during each "run."

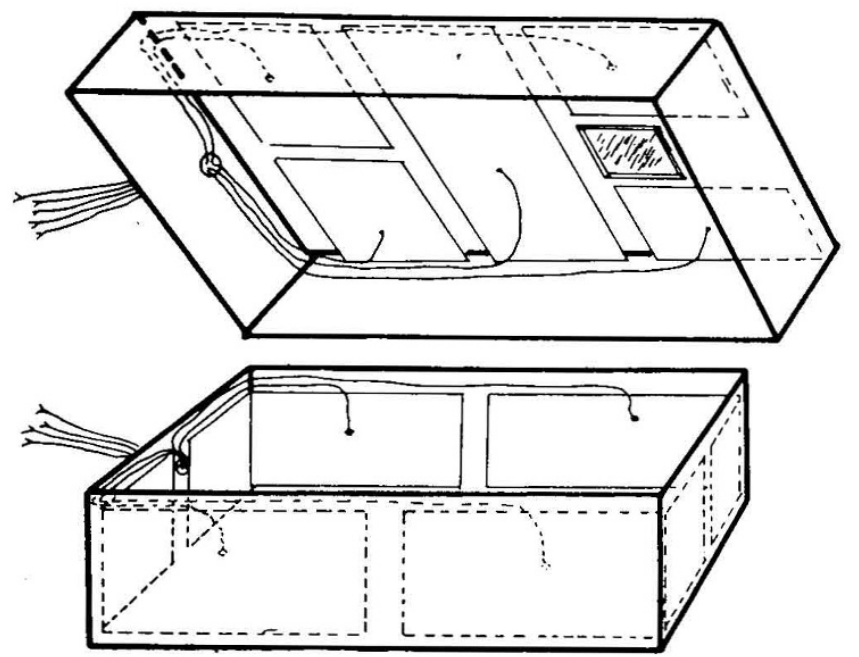

Fig. 2. Gradient calorimeter made by modifying the Gordon-Levine oxygen consumption chamber (5). Indicated here are thermocouples soldered to sheets of copper supported $1 \mathrm{~cm}$ away from the walls of the box. The "artificial baby," an alcohol flame, and, later, premature infants were placed in the box. Measurements were made of temperature gradient across the walls, oxygen-consumption, evaporative water loss, and body temperatures (rectal and skin). From these measurements calculations were made of heat production, heat storage, thermal conductivity, total heat loss, and the fractional loss by evaporation and by radiation and conduction.

adult human beings. The final sentence in this landmark paper reads: "Since most of these observations have been made on infants older than one week and weighing more than 2000 grams, the conclusions should not be extended without reserve to younger or smaller infants." The conclusions were, in fact, not extended to small infants in the first days of life for the next 15 years.

It is of interest that the heavy hand of authoritative opinion played a significant role in blunting the immediate impact of this memorable work. At the time of Dick's studies the conventional wisdom in the United States, concerning the optimum physical conditions for rearing premature infants, was shaped by the results of serial observations made by Blackfan and Yaglou (7) at the Boston Lying-In Hospital from 1926 to 1933. The clinical observations indicated that diarrhea, poor weight gain, and mortality were reduced when body temperature was stabilized in rooms with careful control of humidity. When Dick Day presented his results at a seminar in a prestigious institution, he was told that the measurements in relatively old, healthy, premature infants were interesting but of little practical importance.
He was shown graphic records of premature infants who were thriving despite low but stable body temperature in $60-70 \%$ relative humidity. Dick returned and wrote the caveat in the 1943 paper.

He then went off to wartime service in the U.S. Army Climatic Research Laboratory. Here he worked on the problem of devising gloves to keep the hands of soldiers warm under extreme arctic conditions. He found that a large surface area:volume ratio, the physical handicap of small size that he had documented in premature infants, was the essence of the problem in providing insulation for fingers of the hand. He concluded that insulated gloves for protection against extreme cold were completely impractical-a 44-foot glove finger would be needed to provide comfort at $-10^{\circ} \mathrm{F}$. When Dick made this point to generations of medical students at Columbia after World War II, he showed a photograph of penguins (Fig. 3) who understood the physical principles involved. "They don't bother," Dick said, "with futile attempts to insulate their eggs against the cold; they merely hold them above the freezing ground to reduce conductive heat loss."

When Dick came back to Babies Hospital after the war, he became interested in the problem of kernicterus. He conducted numerous experiments in animals which culminated in his landmark demonstration that bilirubin depressed respiration of ratbrain tissue (8). He postulated that the hemoglobin-derived pigment was the damaging agent to extrapyramidal nuclei, not merely the yellow marker of damage by other mechanisms, as thought heretofore. It is characteristic of Dick that he has never spoken or written about this important piece of work without adding that it was Lytt Gardner who made a suggestion leading to the discovery.

Dick Day was the yeastiest character on the Babies Hospital staff that included unforgettable luminaries like Hattie Alexander, Dorothy Andersen, Jack Caffey, Johnny Little, Howard Mason, Mac McCune, Beryl Paige, and Ashley Weech, during the golden years of the McIntosh Era at Columbia. The lives of those of us who were fortunate to have Dick as a role model were marked indelibly. "Ask an impertinent question, that is the essence of science," Bronowski once said, and I cannot think of a better way to characterize Dick in those days-he asked embarrassing questions, and he has not changed.

Dick sermonized about the scientific method at every opportunity and insisted that the rules of evidence were no different on the ward than they were in the laboratory. Scientific merit,

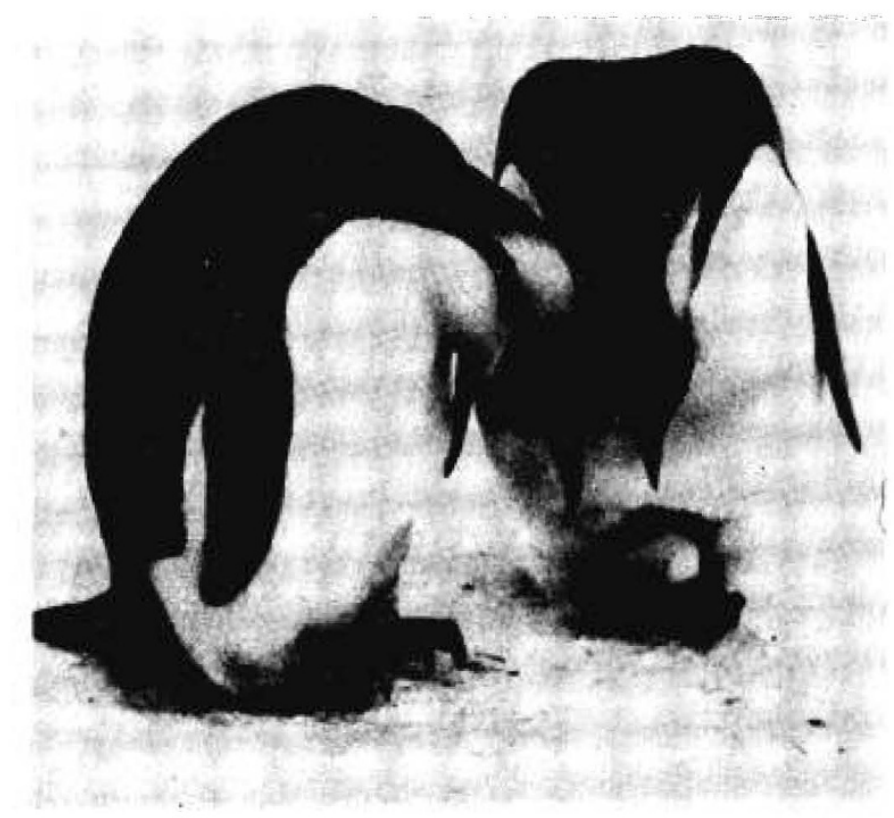

Fig. 3. Day's teaching photograph illustrating the wisdom of penguins. 
he taught, is related to the process by which we go about narrowing our uncertainty about the natural world, not the level of organization of the biological system under study. He inveighed against the destructive snobbery of value-laden terms that were creeping into postwar medical lingo: "preclinical" to mean scientific, and "clinical" to imply nonscientific studies. He emphasized the logical basis for the use of statistics, not the "significance test" flimflam that was coming into vogue. He formed a strong bond with the biostatistician, John Fertig, at P \& S; this link lasted for years and served all of us who followed.

In 1949, a premature infant center designed by Dick Day was opened on the second floor of Babies Hospital. Soon after this, the epidemic of RLF put a pall on the whole venture. It marked the end of the Age of Innocence in newborn matters; and Dick was deeply shaken by this tragedy. In addition, the low salaries at Columbia were completely unrealistic for a man trying to raise three children. Ida Day has told me that Dick drove a beat-up Jeep in those days because it was the only car within his means that could hold his daughter Sally's harp.

About this time the Dean of a prominent out-of-state medical school offered him a job. Dick said he could not accept the offer because the music teachers of his three girls were in New York. The Dean said, "I don't think that's an adequate reason," and Dick replied, "To me it is." When he did accept a chair in 1953, it was in New York, at Downstate Medical School, leaving a gap at Columbia that was never filled. He stayed in New York until his children were grown; then he accepted the post of Chairman at the University of Pittsburgh.

Charley Wood, who went to Pittsburgh to work with Dick, supplied me with some glimpses of this period in Dick's life. The Day's acquired a rambling old house with many more rooms than they needed; nonetheless the rooms always seemed to be occupied. Charley Wood (personal communication) writes: “. . . a common topic of conversation was speculation over the number of keys to the Day house which were handed out to minority groups in town, visiting peace marchers, and various and sundry young people. Apparently the Day's never knew how many guests were sleeping there at any given time." I slept in one of the rooms of that house for several nights and I can confirm Charley's report of a Youth Hostel atmosphere. I was also impressed with Ida's choice of night table reading material for her guests: ban the bomb literature.

George Fetterman (personal communication) remembers how important sailing has been in the Day scheme of things: "Dick was the skipper and Ida the first mate of the good ship Kittiwake. Briney and Suzy, thoroughly ship-broken pet dogs, completed the regular crew. A little added adventure was on tap each day when the dogs were rowed ashore in the dinghy, as soon as the anchor was dropped in a snug harbor. When the shore selected for landing turned out to be the site of someone's garden party, or as it did once, a sheep ranch, the leader of the amphibious maneuver had to be on the alert, ready to summon the landing party back to the dinghy and shove off for the Kittiwake. But local owners were usually understanding, particularly if Ida was in charge. With her sweetness, personality and persuasiveness, land lubbers felt honored by a visit of Briney and Suzy, that doughty duo of nautical dogdom." Incidentally, sweet gentle Ida also had the reputation of mixing the most potent martinis east of the Mississippi.

When Dick Day left academic pediatrics in 1965, to become the Medical Director of Planned Parenthood, there was much head shaking and tongue clicking along the boardwalk in Atlantic City at the spring meetings of the research societies. But the move made perfect sense to anyone who knew of his life-long interest in the welfare of children. All movement is relative; in my view, pediatrics at that time left Dick Day, not the other way around. The reductionist, increasingly narrow view of pediatrics in general, and perinatal medicine in particular, simply does not fit this man whose research interests have ranged from the carbonic anhydrase content of elderberry leaves to acupuncture
(Fig. 4). For the past few years he has been pursuing the relevance of Newton's second law of motion to methods for treating children who have aspirated foreign bodies. A few months ago, I received a letter from Dick in which he announced that he was looking into the practicality of new rowing oar, one that keeps the blade perpendicular to the keel at all times during the stroke (Fig. 5).

The world looks at Dick Day as a founding father of modern perinatology, but that is unfair. The child looks nothing like the father. You have only to review the career of Dick Day to be convinced that he cannot be blamed for the unbridled technological exhibitionism that now distinguishes this flawed activity. (Albert Einstein's condemnation applies perfectly here: "There is a perfection of means and a confusion of goals." In Melville's Moby Dick there is also a relevant passage in which Captain Ahab has a moment of insight and confesses to himself, "all my means are sane, my motive and my object are mad.")

If the Day influence had been dominant, then, to quote Lewis Mumford (9), "A pace of change might have been established in relation to human need. Instead of rapid advances, on the basis of uncoordinated knowledge in specialized areas, there would have been the possibility of a slower, but better coordinated advance that did justice to the processes, functions and purposes of life." Mumford's words fit, to a T, the approach your awardee

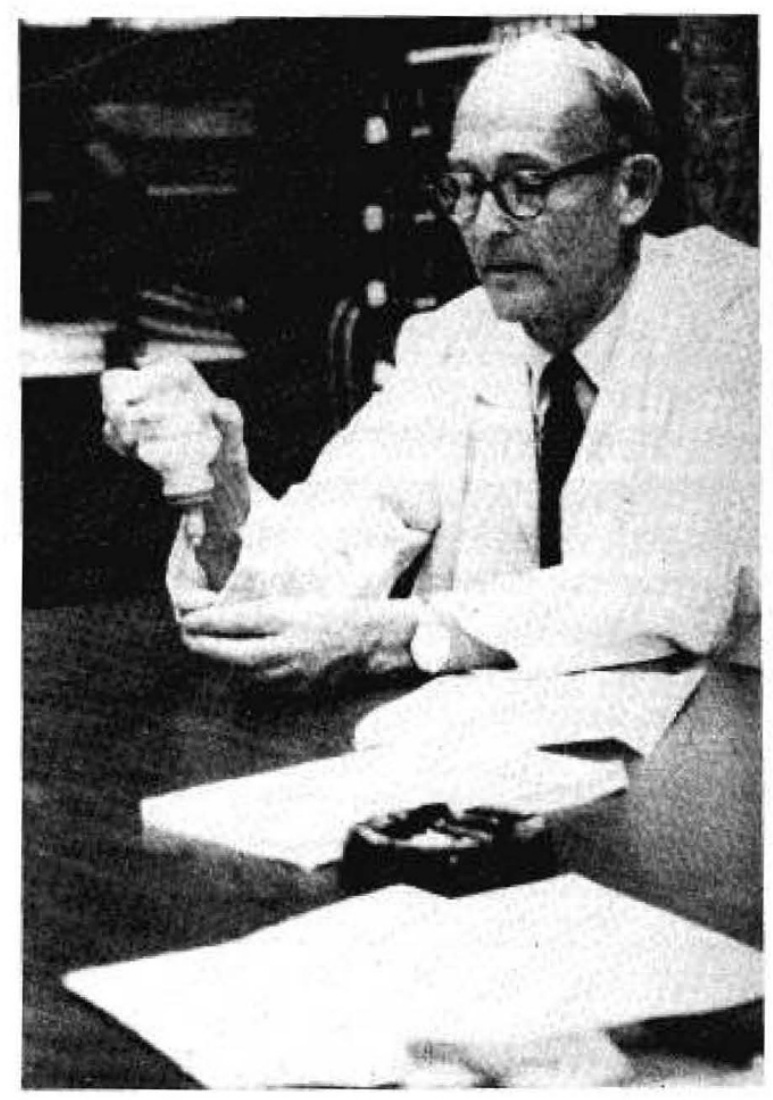

Fig. 4. Richard L. Day.
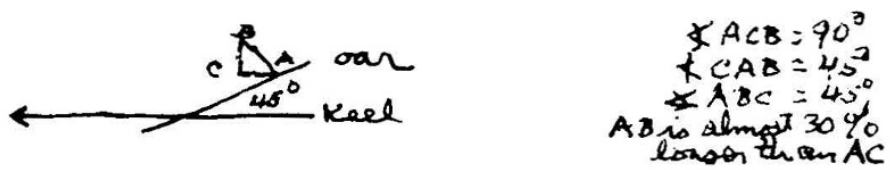

Fig. 5. The Day rowing oar argument: "At the catch the direction of $A \rightarrow B$, the vector pushing the boat forward is $A \rightarrow C$. At midstroke all of the force is making the boat go forward ... I can't calculate the average loss of efficiency but it is surely nearly $15 \%$. My oar blade is always in a position like standard mid-stroke position." 
has followed in studying the problems that beset children and their families.

Dick Day returned to pediatrics in 1968 at the invitation of Horace Hodes at the then new Mount Sinai School of Medicine. He quickly became one of the most popular teachers in the medical school; it was not surprising that the first yearbook published by the students was dedicated to "Doctor Richard Day" (Hodes $\mathrm{H}$, personal communication).

Dick has always been a superb educator; however, his interest was not in "Education" but the promotion of learning. On his rounds the words "What do you think?" were replaced with "What is the evidence?" I remember, as interest in problems of newborn infants began to increase in the 1950 s, he was called upon to give talks throughout the country. He always squirmed in this role. Dick worried about making declarations in the face of inadequate evidence.

Once when Dick and I went to Kentucky to give some talks, he fretted all during the trip. He felt we were doing a dangerous thing to foster belief instead of stirring up doubt and respect for evidence. We decided that after each of us spoke, the other would get up and make challenging remarks to expose the weaknesses in the positions that had just been developed. The presentations went over like a lead balloon-we were never asked to return. But all of Dick Day's fears about pontification have been realized: in response to a profession that abhors uncertainty the way nature abhors a vacuum, applause-junkies and answer-peddlers now rush around the country from resort to resort entertaining and promoting fashionable belief. Indoctrination passes under the name of continuing education. The production of postgraduate courses is now a major growth industry for self-advertisement, engaged in converting American physicians into passive consumers of predigested pap, stifling skepticism, literacy, and selfactuated learning.

In the spirit of what the Howland Award stands for, it is worth celebrating what Dick Day did not do during his long career in pediatrics. He did the basic work in thermoregulation in the newborn, but he did not promote a temperature prescription. $\mathrm{He}$ made basic observations on the effects of bilirubin but he was not the one who proposed the simplistic $20 \mathrm{mg}$ rule for exchange transfusion. He did not proclaim the incredible $40 \%$ oxygen-is-safe dictum, and the list of his wise inactions could go on here. During all of these developments, Dick was emphasizing how little we knew about these matters. "By his restrictions," Goethe wrote, "the master proclaims himself."

As we come close to the moment when Dick Day receives the Howland Award, we sorely miss the presence of Rusty McIntosh. When I wrote to him in December 1985 to ask for some reminiscences for this presentation, he replied, "I'm delighted that Dick Day is to get the Howland Award in ' 86 ... [it's] something I've been working toward for a good long time." In a letter less than 2 weeks before his death in February, he wrote, "I had been hoping to go to Washington for the Howland Award presentation ... I'll be terribly disappointed to miss [it]."

Dick, you are recognized here today for providing some answers to questions. I know that students throughout the world are grateful to you for teaching us all to question answers, and all who profess to have the answers.

\section{REFERENCES}

1. Faber HK, McIntosh R 1966 History of the American Pediatric Society 18871965. McGraw Hill, New York

2. Cone TE Jr 1979 History of American Pediatrics. Little, Brown, Boston

3. Howland J, Marriott WMcK 1916 Acidosis occurring with diarrhea. Am J Dis Child 11:309-325

4. Howland J 1907 The symptoms of status lymphaticus in infants and young children. Trans Am Pediatr Soc 19:51-59

5. Day R, Hardy JD 1942 Respiratory metabolism in infancy and in childhood: XXVI. A calorimeter for measuring the heat loss of premature infants. Am J Dis Child 63:1086-1087

6. Day R 1943 Respiratory metabolism in infancy and in childhood: XXVII. Regulation of body temperature of premature infants. Am J Dis Child 65:376-398

7. Blackfan KD, Yaglou CP 1933 The premature infant: a study of the effects of atmospheric conditions on growth and development. Am $\mathbf{J}$ Dis Child 46:1175-1236

8. Day RL 1954 Inhibition of brain respiration in vitro by bilirubin: reversal of inhibition by various means. Proc Soc Exp Biol Med 85:261-264

9. Mumford L 1946 Values for Survival. Harcourt, Brace, New York 